\title{
High Capacity Ethernet Radio Relay Networks in Mobile Communications
}

\author{
Elena-Mădălina Oproiu ${ }^{1,2}$, Alexandru Vulpe ${ }^{2}$, Ion Marghescu ${ }^{3}$ and Octavian Fratu ${ }^{4}$ \\ ${ }^{1,2}$ University Politehnica of Bucharest,Orange Romania, elena-madalina.oproiu @sdettib.pub.ro \\ ${ }^{2}$ University Politehnica of Bucharest, alex.vulpe@radio.pub.ro \\ ${ }^{3}$ University Politehnica of Bucharest, marion@comm.pub.ro \\ ${ }^{4}$ University Politehnica of Bucharest, ofratu@elcom.pub.ro
}

\begin{abstract}
The present paper studies the main characteristics of digital radio relays used by the largest mobile network operator (MNO) in Romania in order to develop a network supporting the newest technologies available on the market. The main contribution is the design of a high capacity Ethernet radio relay network in an area around Bucharest, Romania. The location was chosen on the criterion that it is a high-density traffic area where high-capacity radio links are in operation and use the newest digital radio relay features that are explained in this paper: high modulation scheme, adaptive radio modulation, radio traffic aggregation and cross-polarization interference cancellation. The network contains PDH and SDH links to transport the entire traffic in the area. We analyse several links between different sites that present particularities in the mobile operator's network. Finally, the most suitable parameters are chosen and the designed radio relay network is presented and analysed. It has been implemented in the MNO's network since 2015.
\end{abstract}

Keywords: Radio Relay, Microwave, AMR, XPIC, RTA, LoS, Traffic, Mobile Network, Capacity, Antenna, ODU, IDU

Received on 13 September 2017, accepted on 23 July 2017, published on 10 January 2018

Copyright (c) 2018 Elena-Madalina Oproiu et al., licensed to EAI. This is an open access article distributed under the terms of the Creative Commons Attribution licence (http://creativecommons.org/licenses/by/3.0/), which permits unlimited use, distribution and reproduction in any medium so long as the original work is properly cited.

doi: 10.4108/eai.10-1-2018.153553

\section{Introduction}

Microwave systems have been in service for many years in networks that are flexible, of high quality and cost efficient. Over the years, these systems have evolved with respect to the supported capacity and features, so that today they can support all types of fixed and mobile voice applications, data and transport protocols. Today, most of the mobile sites in the world are connected to the access domain by digital point-to-point radio systems.

Microwave links have lower implementation costs than fibre optic ones, can be installed very quickly and in hardly accessible areas. Sometimes they are used as backup for fibre, because they are more resilient to earthquakes, landslides and other natural phenomena.

Moreover, fibre is not as flexible as point-to-point radio links when it comes to planning. It is not infrequent for operators to change the site locations and, thus, the fibre link has to be routed to the new locations, which means additional costs and more time consumed. Radio links can be easily reconfigured with small costs and in a short time. The radio link studied in this paper is a point-to-point digital link that operates in frequency division duplex (FDD) mode. The operation of duplexing mean that each radio frequency (RF) channel consists in one pair of frequency for transmission and one for reception[1]. The radio relays used to design the network presented in this paper support both PDH and transport over radio packet data (Ethernet) technologies and they employ special features such as Adaptive Modulation Radio (AMR), Cross-Polarization Interference Cancellation (XPIC), Radio Traffic Aggregation (RTA) or Multiservice Aggregation (MTA).

The paper is organized as follows: Section 2 presents the steps to design and plan a high capacity Ethernet radio-relay network in a city in Romania: Subsection 2.1 presents the link budget of a radio link that consist in choosing the capacity, the frequency and the configuration of the path, Subsection 2.2 presents link calculation between two sites 
representing a special path because of the high capacity (916 Mbps) and the necessary configuration to hold this capacity. Results are shown and discussed in Section 3 and, finally, Section 4 draws the conclusions.

\section{Measurement setup}

This section presents the steps to design and plan a high capacity Ethernet radio-relay network in a city in Romania, by a local mobile network operator. The location was chosen on the criterion that it is a high-density traffic area where high-capacity (max. $916 \mathrm{Mbps)}$ radio links are in operation and use the newest digital radio relay features: high-order modulation (max. 1024-QAM), XPIC, AMR and RTA.

In order to implement the network, MPR Ethernet radiorelays were used and digital radio-relays manufactured by NEC: iPaso and standard NEC. The software application that enables the design of the network is NETCOP and is manufactured by ESG GmbH Germany.

Sites in the city have been indexed from SITE A to SITE $\mathrm{U}$. The sites that are used for leased-lines for the private services offered to clients are termed Point of Interconnect (POI), numbered 1-10. Sites A, B, C are backbone sites because they are linked to the national optic fibre network. They aggregate the entire traffic from the city and transport it through the optic fibre network to the central point. Other important transmission nodes are SITE D, SITE I and SITE $E$ that each take a large part of the traffic in the area. In the city, most of the sites generate traffic from the BTS, NodeB, eNodeB and WiMAX equipment. Fig.1 shows equipment used in each site and total traffic generated by these.

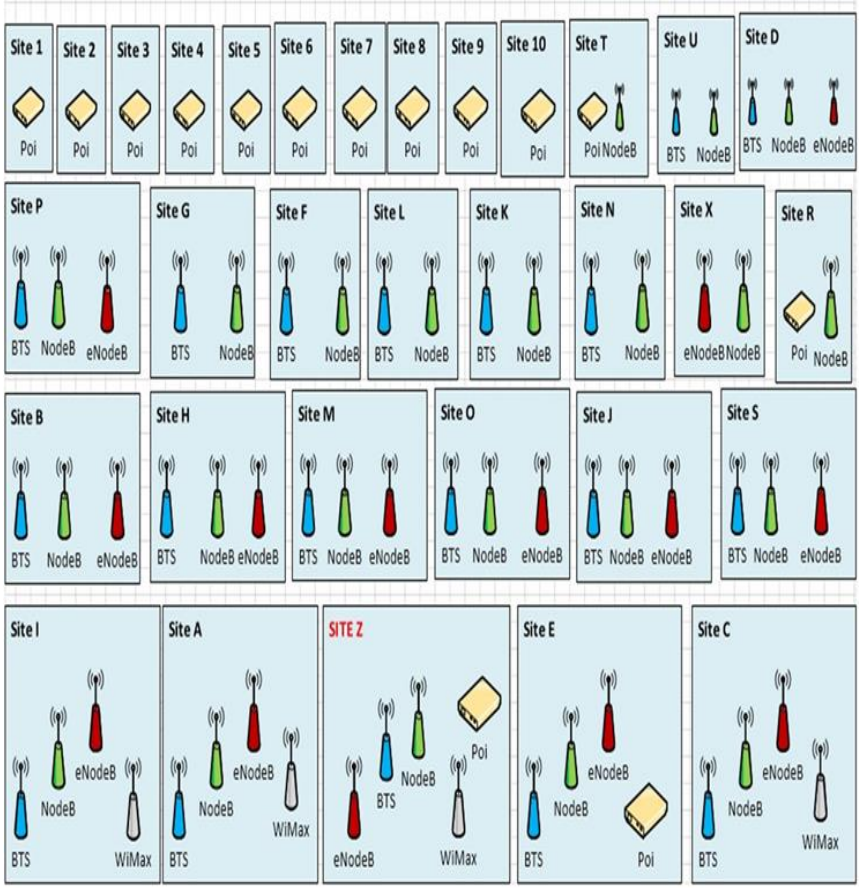

Figure 1. The equipment used and traffic generated on each site

\subsection{Link Budget}

On average, there are two Base Transceiver Station (BTS) cabinets in the Orange site (one for the $900 \mathrm{MHz}$ band, and the other for the $1800 \mathrm{MHz}$ band). Each cabinet has two E1 ports for voice and data traffic. In total we need a $4 \mathrm{E} 1$ transport capacity (meaning approx. $8 \mathrm{Mbps}$ ). After some simple internal calculations, the operator comes to the conclusion that the necessary capacity for dedicated data subscriber access varies from site to site, according to their requirements, ranging from $256 \mathrm{kbps}$ to $350 \mathrm{Mbps}$.

As noticed in Table 2 and 3, A-B, B-C and A-C are SDH radio links which comply with the same propagation principles as other radio links, the only difference being that the traffic type is optical with a capacity of 1 STM1, meaning 155 Mbps. They are designed this way because they aggregate an important amount of traffic which is carried directly into the main optic fibre network core, where the traffic can be carried over two routes: main and spare. Next, starting from the previous data, the radio link budget has to be determined. The budget will take into account the necessary link capacity, equipment capacity and maximum coverage at a certain operating frequency.

Therefore, choice of transmit frequency is done according to the radio link distance. For example, for a Line of Sight (LoS) distance of $2 \mathrm{~km}$, ODUs in the $38 \mathrm{GHz}$ frequency band will be used and for a LoS distance of $15 \mathrm{~km}$, ODUs in the $15 \mathrm{GHz}$ frequency band will be used. In Table 1 we can observe the dependencies between frequencies (used in our network) and distance. Each site has its GPS coordinates in the NETCOP software, and whether or not there is LoS between two sites is determined based on these coordinated. All the links in the designed network have LoS between them. This is reassured by going into the field and doing a site survey at each of the sites to check LoS.

\section{Table 1. Dependencies between frequencies and distance}

\begin{tabular}{ccc}
\hline Frequency $[\mathrm{GHz}]$ & Colour & Distance $[\mathrm{km}]$ \\
\hline 38 & blue & 3 \\
\hline 25 & yellow & $4 / 5$ \\
23 & Red cherry & $6 / 7$ \\
18 & violet & $10-15$ \\
15 & green & $15-20$ \\
13 & black & $35-45$ \\
6.7 & cyan & 45 \\
\hline
\end{tabular}

We can use multiples configurations of radio links. The most used configuration is $1+0$ and it is formed by one antenna, one ODU and one IDU in both parts (transmission and reception) using the same polarization as we can see in Fig. 2 [2]. 


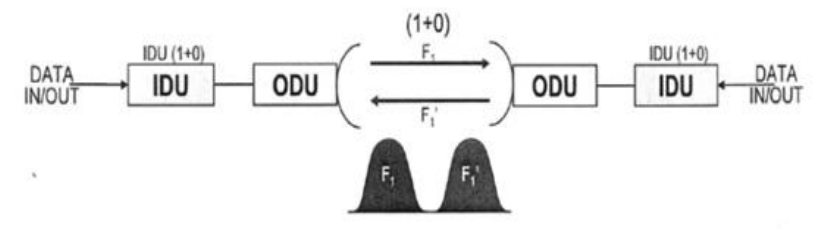

Figure 2. Radio link in $1+0$ configuration

We also used in our network the $2+0$ configuration with XPIC that is formed by two parallel links that used $1+0$ configuration, but with a common IDU. That configuration need one IDU, two ODUs and a dual-pol antenna on both sides. For the transmissions we used the same radio channel F1 but in different polarizations: the F1 channel transmits data on a direction polarized vertical and in parallel it transmits data on another direction polarized horizontally. OMT (Orthogonal Mode Transductor) separates horizontal polarization from the vertical polarization. On the IDU arrive data on F1(V) and F1(H), but with the help of XIF cable it make the difference between data: in the direction of the ODU polarized vertically it received F1(V) like helpful signal and F1(H) like perturbation and it is eliminated. The same thing happens on the direction of the ODU polarized horizontally [2]. The main advantages of this configuration are that we can transmit big capacities over the air and we can save radio spectrum because the transmissions on the both sides are made on the same channel.

\subsection{Link designed between Site $E$ and Site $Z$}

Let's consider, for example, the E-Z link, which has greater interest because of the high capacity (916 Mbps) and the necessary configuration to hold this capacity. This capacity can be assured by using iPasolink equipment with a $2+0$ configuration with XPIC using 1024-QAM modulation and RTA techniques.

First of all, the existence of LoS is checked using NETCOP with the initial design data. We find that there is LoS between the two sites. Also, we obtain that the radio link distance is $3.812 \mathrm{~km}$. This means that we could use transmit frequencies of 25 or $23 \mathrm{GHz}$ to ensure optimum transmission. However, we must also take into account another aspect in choosing the transmit frequency: radio spectrum availability in the link sites. We can see in Fig.4 that in site $\mathrm{E}$ there is a radio link in the $15 \mathrm{GHz}$ band, and one in the $25 \mathrm{GHz}$ band, so, we could use 23 or $25 \mathrm{GHz}$. The problem remains in site $\mathrm{Z}$, because this aggregates several links in the 23 and $25 \mathrm{GHz}$ band so that means it is next to impossible to find an available frequency with 56 $\mathrm{MHz}$ channel spacing (these links cannot be seen in Fig. 4 because they belong to another area in the city; we still have to take these into account when designing new radio links in the border area, because site $\mathrm{Z}$ is at the border of two large areas in the city).

Taking into account all that was previously mentioned, we will use the $18 \mathrm{GHz}$ frequency for the radio link. Usually this frequency is used for links with a distance of 10-15 km and antennas with a higher radius are used (usually 0.6-1.2 $\mathrm{m}$ in diameter). This doesn't mean they cannot be used for a smaller distance like in our case.

In order to find the optimum antenna, the radio link budget for the SITE E - SITE Z radio relay was calculated, taking into account different possible antenna radii. First, we choose antenna with a diameter of $0.3 \mathrm{~m}$ at both ends and we obtain the radio link budget parameters generated by the Netcop report. We obtain that the Received Signal Level (RSL) is $-45.46 \mathrm{~dB}$ and there is a link availability of 99.998 when there is a TX power of $16 \mathrm{~dB}$. The signal level is not enough (the optimum level agreed in the mobile operator's network is $-39 \mathrm{~dB}$ ) and the link availability is not acceptable, so these aspects can be further enhanced. Next, we will try an antenna with a radius of $0.6 \mathrm{~m}$ in site $\mathrm{E}$, and one with a radius of $0.3 \mathrm{~m}$ in site $\mathrm{Z}$. Modifying the antenna diameters is the only option to enhance radio link performance, because only a channel spacing of $56 \mathrm{MHz}$ and 1024-QAM modulation can be used for ensuring this great capacity.

\begin{tabular}{|c|c|c|}
\hline \multicolumn{3}{|l|}{ 458Mb@IHG+EA [1024QAM : undefined] } \\
\hline \multicolumn{3}{|l|}{ General } \\
\hline Free Space Path Loss [dB] & 125.69 & \\
\hline Atmospheric Absorption Loss [dB] & 0.09 & \\
\hline Rain Attenuation [dB] & 8.65 & \\
\hline Tx Power (Site A/B) [dBm] & 16.00 & 16.00 \\
\hline Rx Threshold $10 E-3$ (Site A/B) [dBm] & -58.50 & -58.50 \\
\hline $\operatorname{EIRP}($ Site $A / B)[\mathrm{dBm}]$ & 52.79 & 49.80 \\
\hline Tx Branching Loss (Site $A / B)[d B]$ & 0.00 & 0.00 \\
\hline Rx Branching Loss (Site $A / B)[d B]$ & 0.00 & 0.00 \\
\hline Received Signal Level (Site A/B) [dBm] & -39.19 & $-39,19$ \\
\hline Total Threshold Degradation (Site A/B) [dB] & 0.00 & 0.00 \\
\hline Total $\mathrm{C} / \mathrm{I}($ Site $\mathrm{A} / \mathrm{B})[\mathrm{dB}]$ & -39.19 & -39.19 \\
\hline Thermal Fade Margin (Site $A / B)[d B]$ & 19.31 & 19.31 \\
\hline 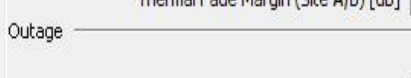 & {$[\%]$} & [seconds/year] \\
\hline Worst Month Multipath Outage & 0.000019 & 0.50 \\
\hline Annual Multipath Outage & 0.000002 & 0.50 \\
\hline Annual Rain Outage & 0.000860 & 271.53 \\
\hline Final Performance (total) - & 99.999138 & \\
\hline SES Probability [\%] & 0.000845 & \\
\hline SES Event [seconds/month] & 22.22 & \\
\hline SES Probability without Diversity [\%] & 0.000845 & \\
\hline Unavailability Probability [\%] & 0.000017 & \\
\hline Unavailability [min/year] & 0.09 & \\
\hline Unavailability Probability without Diversity [\%] & 0.000017 & \\
\hline \multicolumn{3}{|l|}{ ITU-target Objective } \\
\hline Objective & G.826 National Portion & \\
\hline Block Allowance Factor & 0.185000 & \\
\hline SES Probability [\%] & 0.037000 & \\
\hline SES Event [seconds/month] & 959.04 & \\
\hline Unavailability Probability [\%] & 0.033600 & \\
\hline Unavailability [min/year] & 176.73 & \\
\hline
\end{tabular}

Figure 3. The report generated by Netcop at the design of link $\mathrm{E}-\mathrm{Z}$ with with one $0.3 \mathrm{~m}$ diameters antenna and one $0.6 \mathrm{~m}$ diameters antenna 
With $0.6 \mathrm{~m}$ diameter antenna in site $\mathrm{E}$ (Fig.3) we obtained a RSL improvement of over $5 \mathrm{~dB}(\mathrm{RSL}=-39.19$ $\mathrm{dB})$ and the radio link availability rises to 99.999138 (meaning that $0.09 \mathrm{~min} / \mathrm{year}$ the link is unavailable). These results are deemed acceptable by the mobile operator's standards and the link can be implemented using these parameters.

\section{Results}

Fig.4 shows the designed radio relay network for the considered city. Sites are geographically positioned, according to GPS coordinates. The sites are linked for transport according to LoS existence or non-existence. Site B and Site D aggregate the most links because of the high probability of LoS.

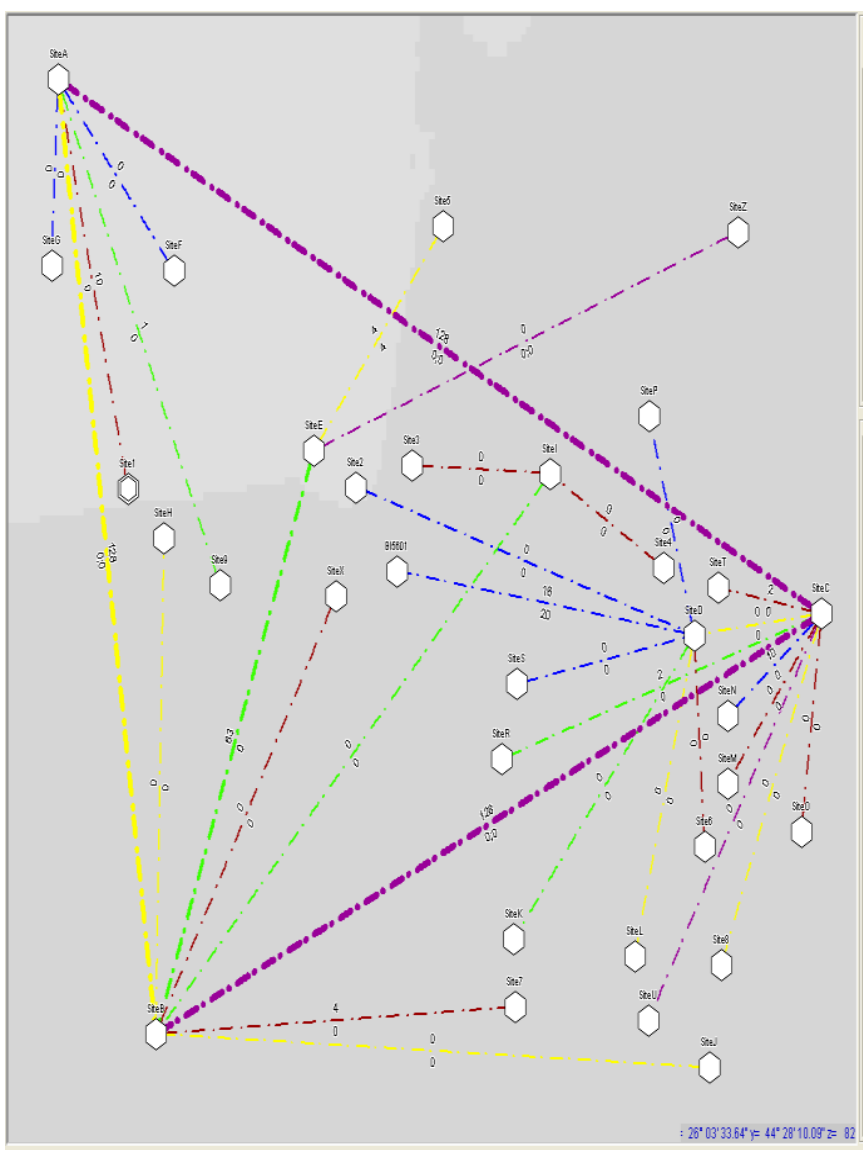

Figure 4. The projected radio Ethernet relay network in Netcop

Colour code used to display radio links is according to Table 1 . We can thus notice that radio relays are used with transmit frequencies of 38, 25, 23, 18, $15 \mathrm{GHz}$.

The same way as for the E-Z link we computed the radio link budget for all LoS links necessary to aggregate traffic from sites to the core network for the city. Radio link performance parameters for the radio relays are given in two tables. Table 2 shows radio parameters that need to be configured for equipment as well as the length of the antennae necessary for obtaining parameters in Table 3 .

\section{Conclusions}

This paper presented the steps of the projection of a radio Ethernet relay network that used big capacities and it is functional in present in the network of a mobile operator from Romania. We made the link budget for every path between the sites of the city taking in account the initial data of projection, that include the type of generated traffic by each site on this area and the capacity required to transport this traffic. We analysed, particularly, the link

between sites that present some singular particularities in our network: it is in $2+0$ configuration with XPIC, uses radio techniques like RTA, AMR and offers, in present, in the mobile operator network, the largest capacity provided on the radio environment: $916 \mathrm{Mbps}$.

Taking into account the aspects presented in this paper, we think that the microwave links represents an efficient and flexible solution for the development of one telecommunications network (especially on access part) that can hold all the types of services: voice, data and fixed services from second, third or four generation.

\section{Acknowledgements.}

This work was been done in collaboration with my colleagues from Orange Romania Transmission Team. It has been funded by Orange Educational Programme Engineering from Orange Romania. It has also been partially funded by UEFISCDI Romania under grants no. 20/2012 "Scalable Radio Transceiver for Instrumental Wireless Sensor Networks - SaRaT-IWSN"' and 262EU/2014 eWALL support project and by the European Commission by FP7 IP project no. 610658/2013 "eWALL for Active Long Living - eWALL"

\section{References}

[1] D. C. Livingston, The Physics of Microwave Propagation, GTE Technical Monograph,General Telephone \& Electronics Laboratories, Bayside, NY, May 1967

[2] NEC Corporation- iPASOLINK 400A, 6 - 42GHz 10 - 500 Mbps DIGITAL RADIO SYSTEM

[3] Alcatel Lucent training radio, Orange Romania 2013

[4] ITU-T Recommendation G.811, Timing characteristics of primary reference clocks 
Table 2. Radio parameters of the links projected, part I

\begin{tabular}{|c|c|c|c|c|c|c|c|c|c|}
\hline \multirow[b]{2}{*}{ 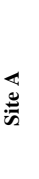 } & \multirow[b]{2}{*}{ ڤै } & \multicolumn{4}{|c|}{ SITE A } & \multicolumn{4}{|c|}{ SITE B } \\
\hline & & 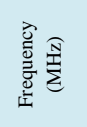 & $\begin{array}{l}\text { 胥 } \\
\text { 善 } \\
\text { 总 }\end{array}$ & 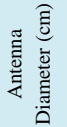 & 要 & 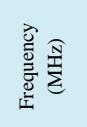 & 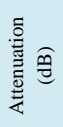 & 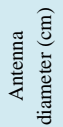 & 言 \\
\hline $\mathbf{A}$ & B & 25571 & 0 & 60 & 170.23 & 24563 & 0 & 60 & 350.24 \\
\hline $\mathbf{A}$ & $\mathrm{C}$ & 19480 & 0 & 60 & 113.61608 & 18470 & 0 & 60 & 293.65118 \\
\hline B & $\mathrm{C}$ & 18360 & 0 & 120 & 247.30148 & 19370 & 0 & 60 & 67.27121 \\
\hline $\mathbf{A}$ & G & 37765 & 15 & 30 & 210.2524 & 39025 & 15 & 30 & 30.24978 \\
\hline $\mathbf{A}$ & $\mathrm{F}$ & 39032 & 10 & 30 & 316.21 & 37772 & 10 & 30 & 136.2 \\
\hline $\mathbf{A}$ & 1 & 23299.5 & 10 & 30 & 344.5301 & 22291.5 & 10 & 30 & 164.52677 \\
\hline B & $\mathrm{H}$ & 25571 & 0 & 60 & 170.23 & 24563 & 0 & 60 & 350.24 \\
\hline B & E & 14725 & 2 & 30 & 208.89865 & 15215 & 2 & 30 & 28.89026 \\
\hline B & $\mathrm{X}$ & 23282 & 0 & 60 & 97.75772 & 22274 & 0 & 30 & 277.79098 \\
\hline B & 7 & 23556 & 6 & 30 & 234.56 & 22302 & 6 & 30 & 215.29998 \\
\hline B & $\mathrm{J}$ & 25571 & 3 & 30 & 154.67 & 24563 & 0 & 30 & 267.45 \\
\hline $\mathbf{E}$ & 5 & 25599 & 14 & 30 & 5.62 & 25599 & 14 & 30 & 5.62 \\
\hline $\mathbf{E}$ & Z & 19370 & 0 & 60 & 72.37 & 18360 & 0 & 30 & 252.4 \\
\hline I & 3 & 22127 & 0 & 30 & 211.25845 & 23135 & 0 & 30 & 31.23901 \\
\hline I & 4 & 22141 & 4 & 20 & 104.31 & 23149 & 4 & 20 & 284.31 \\
\hline D & 2 & 37800 & 5 & 30 & 277.77 & 39060 & 5 & 30 & 97.75 \\
\hline D & $\mathrm{S}$ & 39021.5 & 8 & 30 & 84.98 & 37761.5 & 8 & 30 & 264.99 \\
\hline D & $\mathrm{K}$ & 18346.25 & 0 & 30 & 31.27 & 19356.25 & 0 & 30 & 211.28 \\
\hline D & $\mathrm{L}$ & 24619 & 20 & 30 & 234.44764 & 25627 & 20 & 30 & 54.4447 \\
\hline D & $P$ & 37800 & 8 & 30 & 52.87 & 39060 & 8 & 30 & 232.88 \\
\hline D & 6 & 23306.5 & 10 & 30 & 273.84758 & 22298.5 & 10 & 30 & 93.83864 \\
\hline $\mathbf{C}$ & D & 24622.5 & 0 & 30 & 126.42 & 25630.5 & 0 & 30 & 306.44 \\
\hline C & $\mathrm{T}$ & 22134 & 9 & 30 & 187.4618 & 23142 & 9 & 30 & 7.46096 \\
\hline $\mathrm{C}$ & $\mathrm{R}$ & 15215 & 0 & 60 & 134.41441 & 14725 & 0 & 60 & 314.46647 \\
\hline C & $\mathrm{N}$ & 37772 & 2 & 30 & 168.73562 & 39032 & 2 & 30 & 348.738 \\
\hline $\mathbf{C}$ & M & 23149 & 2 & 30 & 240.24073 & 22141 & 2 & 30 & 60.22317 \\
\hline $\mathbf{C}$ & $\mathrm{U}$ & 18442.5 & 7 & 30 & 206.4096 & 19452.5 & 7 & 30 & 26.40731 \\
\hline
\end{tabular}

Table 3. Radio parameters of the links projected, part II

\begin{tabular}{|c|c|c|c|c|c|c|c|c|c|}
\hline 岕 & ڤै & 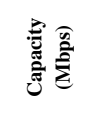 & $\frac{\bar{g}}{\vec{g}}$ & 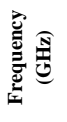 & 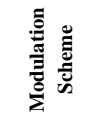 & 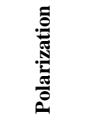 & 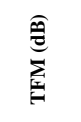 & 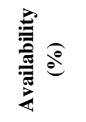 & 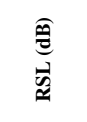 \\
\hline $\mathbf{A}$ & B & $2 *$ STM1 & SDH & 25 & 128QAM & $\mathrm{VH}(2+0)$ & 23.469 & 99.999 & -38.9723 \\
\hline $\mathbf{A}$ & $\mathrm{C}$ & $2 *$ STM 1 & SDH & 18 & 128QAM & $\mathrm{VH}(2+0)$ & 22.344 & 99.998 & -39.1995 \\
\hline B & $\mathrm{C}$ & $2 *$ STM1 & SDH & 18 & 128QAM & $\mathrm{VH}(2+0)$ & 34.850 & 99.999 & -39.467 \\
\hline $\mathbf{A}$ & G & 64.8 & MPR & 38 & 64QAM & $\mathrm{H}$ & 34.005 & 99.997 & -39.321 \\
\hline $\mathbf{A}$ & $\mathrm{F}$ & 111.36 & MPR & 38 & 32QAM & $\mathrm{V}$ & 35.950 & 99.999 & -37.452 \\
\hline $\mathbf{A}$ & 1 & 20 & NEC & 23 & 4QAM & V & 49.204 & 99.999 & -39.513 \\
\hline B & $\mathrm{H}$ & 111.36 & MPR & 25 & $32 \mathrm{QAM}$ & $\mathrm{H}$ & 22.271 & 99.996 & -37.467 \\
\hline B & $\mathrm{E}$ & 182.3 & IPASO & 15 & 256QAM & V & 33.678 & 99.997 & -38.678 \\
\hline B & $\mathrm{X}$ & 182.3 & IPASO & 23 & 256QAM & V & 29.456 & 99.999 & -39.045 \\
\hline B & 7 & 40 & NEC & 23 & 16QAM & $\mathrm{H}$ & 22.215 & 99.996 & -39.456 \\
\hline B & $\mathbf{J}$ & 136.6 & IPASO & 25 & 64QAM & V & 35.839 & 99.999 & -40.023 \\
\hline $\mathbf{E}$ & 5 & 20 & NEC & 25 & 16QAM & $\mathrm{V}$ & 35.0388 & 99.997 & -38.980 \\
\hline $\mathbf{E}$ & $\mathbf{Z}$ & $\begin{array}{c}916(2+0) \\
458 * 2\end{array}$ & IPASO & 18 & 1024QAM & $\mathrm{VH}(2+0)$ & 29.78 & 99.988 & -39.66 \\
\hline I & 3 & 80 & NEC & 23 & 32QAM & $\mathrm{V}$ & 32.660 & 99.995 & -38.543 \\
\hline I & 4 & 40 & NEC & 23 & 16QAM & $\mathrm{H}$ & 22.215 & 99.998 & -39.238 \\
\hline D & 2 & 20 & NEC & 38 & 16QAM & $\mathrm{V}$ & 44.751 & 99.9996 & -39.956 \\
\hline D & $S$ & 65.28 & MPR & 38 & 64QAM & $\mathrm{V}$ & 34.1762 & 99.999 & -39.494 \\
\hline D & K & 136.6 & IPASO & 15 & 64QAM & V & 32.205 & 99.997 & -39.848 \\
\hline D & $\mathrm{L}$ & 111.36 & MPR & 25 & 32QAM & V & 34.099 & 99.989 & -39.678 \\
\hline D & $\mathrm{P}$ & 87.04 & MPR & 38 & 16QAM & $\mathrm{H}$ & 31.39 & 99.998 & -40.004 \\
\hline D & 6 & 40 & NEC & 23 & 16QAM & $\mathrm{H}$ & 32.077 & 99.999 & -39.786 \\
\hline C & D & 320.1 & IPASO & 25 & 128QAM & $\mathrm{V}$ & 34.782 & 99.999 & -39.658 \\
\hline C & $T$ & 40 & NEC & 23 & 16QAM & $\mathrm{H}$ & 33.675 & 99.995 & -40.023 \\
\hline C & $\mathrm{R}$ & 20 & NEC & 15 & 4QAM & $\mathrm{V}$ & 37.65 & 99.998 & -39.345 \\
\hline $\mathbf{C}$ & $\mathrm{N}$ & 67.7 & IPASO & 38 & 64QAM & V & 31.554 & 99.999 & -38.665 \\
\hline $\mathbf{C}$ & M & 111.36 & MPR & 23 & 32QAM & V & 5.8016 & 99.997 & -39.856 \\
\hline C & $\mathrm{U}$ & 111.36 & MPR & 18 & 32QAM & $\mathrm{H}$ & 5.4973 & 99.997 & -39.496 \\
\hline
\end{tabular}

